\title{
Leer: cresistir o insistir? Los docentes frente a la lectura
}

Jader Rivera Monje

\section{Temores y certezas}

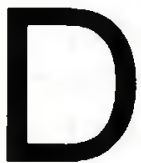

ebo decirles que durante cuatro años trabajé con el Centro Regional para el Fomento del Libro en América Latina, el Caribe, España y Portugal -CERLALC. Desde el 2004, el Ministerio de Educación Nacional, en convenio con este organismo, y en articulación con el Ministerio de Cultura, venía adelantando un proyecto denominado Mil Maneras de Leer. El propósito: fomentar el uso de las bibliotecas públicas municipales en las instituciones educativas, desarrollar hábitos lectores y competencias comunicativas de los estudiantes. Para tal objetivo se dio a la tarea de buscar y contratar a medio centenar de profesionales y artistas en todo el país. Contrario a lo que se creía, nuestro trabajo no se centró en la capacitación de los niños y jóvenes que, según las pruebas SABER, SERCE y PISA, no alcanzaban los niveles de lectura esperados. Todos nuestros esfuerzos debían centrarse en los docentes. Para el CERLAC -como se hizo evidente para mi a lo largo del trabajo- los bajos niveles de lectura y escritura que registraba el pais con respecto a otras naciones del mundo, radicaba no tanto en los estudiantes como en una carencia de hábitos lectores, convicciones y estrategias pedagógicas por parte de los docentes.

Aunque se evidenciaba que no eran los únicos culpables de los bajos niveles de lectura en los estudiantes -estaba en primerísimo lugar la familia-, eran los miembros de la comunidad educativa que tenían el poder de cambiar la situación si se orientaban correctamente. La tarea, sin embargo, no era tan fácil. Recuerdo las primeras instrucciones por teléfono que me dio Corina, la funcionaria que estaba a cargo del proyecto a nivel nacional: "El gremio de los docentes opondrá resistencia -me dijo-. Usted tendrá que convencerlos, tendrá que seducirlos, no sé cómo, pero tendrá que hacerlo." Corina no creyó mucho en mis capacidades. Yo llevaba trabajando 10 años en una finca cafetera, había perdido cierto dominio del lenguaje o no era tan elocuente como ella esperaba. Recuerdo que después de mucho hablar en esa primera entrevista telefónica me dijo que estaba dispuesta a "arriesgarse conmigo". Eso dolió. Pero ella tenía razón, la contratación era un riesgo: yo no tenía experiencia en capacitación de docentes. Lo único que le ofrecia era mi buena voluntad y algunos conocimientos en lectura y escritura.

Le dije a Corina que yo le prometía cumplir con las metas. Ella de inmediato me respondió: "No quiero que me prometa nada. Sólo haga bien el trabajo". Desde aquel día fueron muchos los temores que me asaltaron. Después de 10 años de trabajar en el campo, ¿podría yo lanzarme a capacitar docentes? ¿Eran tan terribles como me lo advirtieron? Recuerdo que apenas terminada la universidad, yo había sido profesor 
en los municipios de El Caguán y Neiva. Había tenido buenas relaciones con los compañeros de trabajo aunque eso sí, se habian aprovechado de mi ingenuidad: terminé dictando dibujo técnico, sociales y francés y como premio de consolación me pusieron a dar algunas horas de lengua castellana. Por otra parte, me delegaron la dirección de los grados más "insoportables", conformados por muchachos de los cuales ninguno quería hacerse cargo. Fue como arrojar carne a los cocodrilos. Creía que me iban a devorar pero salí bien librado. Cumplía con las horas de clase, aunque eso sí, salía con un sentimiento de frustración que me llevó a pensar que yo no servía para docente, que en ese trabajo más que resistencia y disciplina se necesitaba tener vocación. Y esta certidumbre de la vocación como requisito primordial para ejercer la docencia no ha cambiando a pesar de los años.

Ahora me preguntaba si ocurriría algo parecido. En esta ocasión las condiciones de trabajo

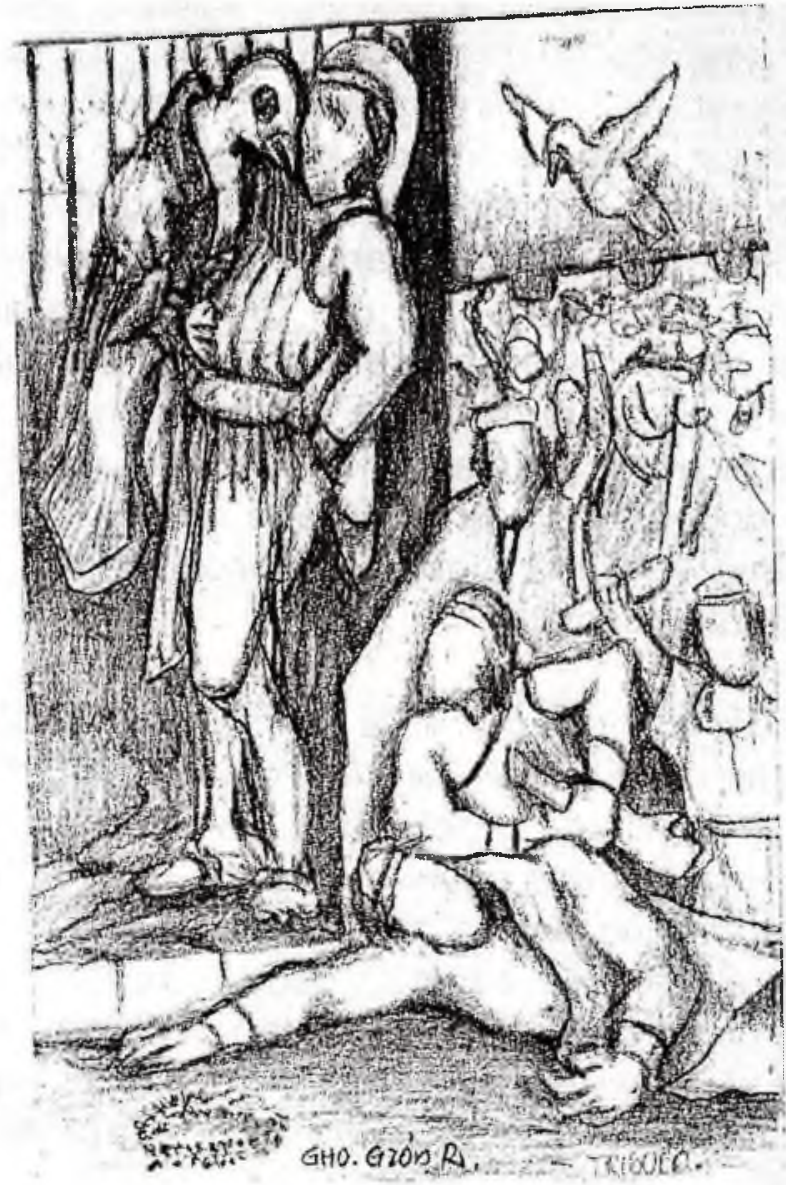

habían cambiado. Ahora yo era profesor de profesores. Eso me asustaba aún más. ¿Qué podía yo enseñarles a docentes que llevaban veinte y hasta treinta años dando clase? "De seguro se lo comen vivo", se burló un amigo en el terminal de transporte cuando emprendía viaje hacia las primeras instituciones educativas que tenía que contactar. Estaban ubicadas en el municipio de La Plata. Llevaba una agenda de trabajo, los resultados de las Pruebas de Estado, SABER y PISA y una presentación en PowerPoint para convencerlos de aceptar el proyecto.

El primero reto era convencer al rector, a los coordinadores académicos, al director de núcleo y al alcalde. Plantearles con claridad el problema que tenían en el municipio y la solución que yo les ofrecía. Sólo tenían que escoger algunos docentes para que asistieran a los talleres que habían sido programados para cuatro meses. Cuando, a pesar de todas las razones que les exponía se mostraban reticentes, sacaba un arma que siempre guardaba para momentos difíciles: les recordaba que yo representaba el Ministerio de Educación y que tendría que hacer un informe sobre los resultados de mi gestión. Expondría con claridad las razones por las cuales ellos habian rechazado el proyecto. Esta última arma sólo la use en contadas ocasiones. La mayoria de directivos y alcaldes huilenses aceptaron de buena voluntad.

\section{Los besos, el libro y la primera infancia}

Al margen de todas las vicisitudes que tuve para convencer a los directivos y alcaldes; $y$, posteriormente a los docentes, los talleres se iniciaron en las fechas acordadas. Me gustaba empezar las sesiones preguntándoles por el primer beso que habian recibido en la vida. Queria que recordaran a qué sabía, qué habían sentido y si les alcanzaba la memoria para describir a esa persona que se había atrevido a besarlos. Entonces los docentes se 
abalanzaban a hablar con picardía de éste u otro detalle, de la noche en que no podían dormir, de las ganas de besar otra vez o de que, sorprendentemente, como dijera una profesora, al único hombre que habían besado en la vida era al esposo. Esto último causaba mucha risa, admiración y comentario tendenciosos como "si usted ha besado sólo a un hombre, ¿cómo sabe que sus besos son buenos comparados con los otros que nunca recibió?"

A estas alturas de la charla y, pese a los buenos ánimos de todos, los docentes se preguntaban ¿qué tiene que ver los besos con los libros y la biblioteca?. Y acaso pensaban con perspicacia: "Este tal vez es otro de tantos proyectos absurdos que nos manda el Ministerio" Yo, por supuesto, los ignoraba. Continuaba indagando por el primer amor, por los detalles, por las citas, por las sensaciones. Casi todos coincidian en que fue maravilloso y que recordaban eso con suma claridad. Entonces me daban pie a preguntarles por el primer libro que habían leido. Muchos mencionaron con alegría los nombres de los libros y las cartillas de primaria, citaban de memoria poemas y rimas, páginas completas de novelas. Yo avanzaba aún más y les preguntaba por qué evocaban esos libros con tanta alegría y entonces se hacía evidente la presencia de un ser amado: la amorosa profesora de primaria, el estricto pero inteligente y sensible profesor de secundaria, el padre que le leía cuentos a su hija antes de acostarse o la ovación de la que fue objeto aquel día en que recitó de memoria a Rafael Pombo. Los libros y la buena disposición hacia la lectura estaban incondicionalmente relacionados con el afecto $y$, en particular, con la primera experiencia que tenemos en la infancia. Esa era la primera y gran lección que debian recibir los docentes. Ser conscientes que no se le puede obligar a leer a un niño si en su corazón ese libro le produce miedo, dolor o hastío. Cuando le pregunté a una profesora la razón por la cual decía odiar El Principito, de Antoine de SaintExupéry, el mismo autor que un día dijera: "La lectura es un acto que, de manera inconsciente, ata al lector. No se trata de interesar al lector sino de hechizarle."; respondió simplemente que nunca lo habia entendido $y$, sorprendentemente, le parecía estúpido, no le decía nada, no estaba conectado con su vida. Ese día, indagando en su pasado descubrió que su profesora de primaria la obligó a leer dicho libro y la puso en ridículo delante de sus padres y compañeros. En ese momento todos fuimos conscientes del poder que tenían los docentes sobre los niños. Podemos convertir los libros en instrumentos de placer o tortura. Podemos estimular o frustrar a un gran lector aún antes de que nazca.

Yo quisiera citar aquí a Yolanda Reyes y, particularmente el ensayo denominado "Cuando leer es más que hacer tareas"1 pues me sirvió de gran ayuda a la hora de convencer a los docentes que el problema de la lectura y la escritura en los estudiantes tenía su origen en la primera infancia, en su relación vital con la familia y los adultos cercanos. Los primeros que deben crear hábitos lectores a partir del afecto son los padres y hermanos, tíos e inclusive los abuelos. El niño no nace odiando los libros ni la lectura. Somos nosotros los que introducimos, mediante nuestros métodos de represión educativa, esas fobias en su corazón.

"Si no hay un hilo fuerte -nos dice Reyes-

\footnotetext{
'Reyes Yolanda. "Cuando leer es más que hacer tareas". Bajado el dia 7 de febrero de: http://mww.nuevashojasdelectura.com/paginas/ dossier_R3.html. Se puede consultar también el documento "La lectura en a primera infancia", de la misma autora en la siguiente dirección: http://www.cerlalc.org/redplanes/secciones/biblioteca/reyes_lectura_primera_infancia.pdf
} 
que conecte desde temprano la lectura con el desciframiento vital y si esa conexión no se continúa ofreciendo a los niños, mediante voces de maestros y de padres que les leen historias significativas mientras ellos conquistan progresivamente las arbitrariedades del código escrito, leer puede convertirse en una actividad carente de sentido. Significará hacer ruidos con la boca; responder a los interrogatorios sobre las ideas principales; perder el valioso tiempo para jugar y soñar frente a textos insulsos; tartamudear de pánico delante del resto de la clase, garabatear planas y muchas otras actividades diferentes a descifrarse, conocerse y explorar el mundo."

Por el contrario, continúa,

"Al no existir presiones alfabéticas, durante la primera infancia es posible concentrarse en el vínculo afectivo que conecta a las palabras, las historias y los libros con los seres humanos. Vincular los libros con el afecto de los seres más importantes y queridos, permite crear un hilo emocional para afrontar los retos posteriores de la alfabetización, pues antes de ingresar al código escrito, el niño ha tenido la oportunidad de experimentar las compensaciones vitales de la lectura."

Luego de estas reflexiones, los docentes eran víctimas de un sentimiento de impotencia. Consideraban que los padres de familia no contribuían en nada al establecimiento de lazos afectivos entre el libro y el niño, pues en su mayoria no les gustaba leer y continuamente repetian el esquema con el que los habian educado: el método tradicional de educación basado en la represión, repetición y el desciframiento de códigos sin conexión con la vida. Los profesores se preguntaban: ¿si los hábitos lectores se instauran en la primera infancia, qué podían hacer ellos cuando llegaban a sus aulas niños indiferentes e inclusive rebeldes frente al libro? Lo primero que deben hacer los docentes -les sugerí- es no repetir esta actitud: cruzarse de brazos so pretexto que las anomalías que presenta el estudiante es consecuencia de una familia disfuncional o que, para el caso de los niños que pasaban a secundaria, era producto del pésimo trabajo del profesor anterior. Yo les pedi el favor dejaran de lado tal actitud pues en nada contribuia a solucionar el problema. Lo que tenían que hacer era investigar la causa de las fobias, enamorarse ellos mismos de la lectura y la escritura y transmitir ese afecto a los niños esa pasión que no recibieron de la familia ni de los primeros profesores en el aula de clase.

El amor no caduca con la edad, les dije como si fuera una gran noticia. Siempre estamos necesitados de cariño y no desaprovechamos la más mínima oportunidad para que nos amen. Si los hábitos lectores están conectados con el afecto, entonces, tenemos lo necesario para hacer nuestro trabajo. $Y$ agregué: la comunicación, la conexión con los otros seres se hace a través de las palabras, los matices de la voz, los gestos, el brillo de los ojos, los brazos, las manos, la ropa. Cuando nos apasionamos, cuando estamos convencidos de lo que leemos, y gozamos leyendo en voz alta a nuestros alumnos, eso "se pega", los alumnos descubren por primera vez que los libros constituyen una fuente placer. ¿Qué tiene ese libro que emociona tanto al profesor al punto de hacerlo llorar o reír?, se pregunta intrigado el alumno. El profesor puede aprovechar la oportunidad para tender trampas: mentir sobre el libro, dejar en vilo la narración. Retarlos a que descubran en que pasaje ha falseado la historia, etc. Parafraseando a Antoine de Saint-Exupéry les aconsejé que los libros no deben tanto despertar el interés de los estudiantes como hechizarlos. Pero primero los docentes deben ser víctimas gozosos de ese hechizo.

Me asaltó de imprevisto una inquietud. Me 
pregunté: ¿cómo ser un docente víctima gozoso de ese hechizo si ni en la escuela, ni en el colegio, y acaso ni en la universidad se presentaron las circunstancias apropiadas para que sucediera el milagro?. Muchos de los docentes con los que trataba se habian aficionado a la lectura en la madurez. ¿Qué había pasado?. Las respuestas fueron inesperadas. Un profesor de filosofía en un municipio del sur me confesó que luego de estrellarse estrepitosamente en una moto quedó por muchos meses reducido a una cama. Durante ese tiempo se dedicó a lamentarse de la situación. Un día un amigo le aconsejó que se distrajera leyendo uno que otro libro en vez de estar quejándose todo el tiempo. Cuando por fin pudo caminar y reanudar su vida, se habia convertido en lector asiduo. La lectura se habia convertido en un hábito y el libro en una fuente de placer. Le pregunté con cierta malicia si en un su casa no había televisión. Dijo que si pero después de verla las veinticuatro horas del día empezó a aburrirse, los programas se tornaron estúpidos y predecibles porque repetían una y otra vez los mismos esquemas. Un día decidió apagar la televisión. Como no le quedaba otra cosa en qué distraerse, acudió a los libros.

Pero el amor también influyó en la creación de hábitos lectores de algunos docentes en la edad adulta. Un dia se sintieron tiernamente, "estúpidamente enamorados", me dijeron algunos. Claro, enamorados no de un hombre o una mujer cualquiera, sino de un hombre o una mujer que amaba los buenos libros y sobre todo exigía que su enamorado o enamorada también se acercara a ellos. Todo empezó con un poema leído en voz baja en el oído. Era la poesia puesta al servicio del amado. La poesía como instrumento para acceder al otro. Posteriormente llegó la prosa en sus múltiples expresiones literarias y académicas. La relación amorosa posibilitó el cambio, concluyeron. Les pregunté qué habia pasado con esos amores. Dijeron que se habían acabado a los pocos meses pero que les había quedado ese gusto por leer, por hacer de la lectura algo agradable.

\section{Los docentes y los modelos lectores}

Leemos por gusto o por necesidad ${ }^{2}$. Por gusto puesto que nos sentimos atraídos por ciertos textos que nos proporcionan placer y a la vez llenan vacíos cognitivos. Tal como acontece con el aficionado a la pintura que se planta voluntariamente frente a las obras de arte y experimenta cierto estremecimiento gozoso al percibir las formas, los colores, los volúmenes $y$, en un instante de revelación, comprender en su totalidad la obra. Pero también leemos por necesidad para acceder a la universidad, convertirnos en profesionales y ser exitosos. Leer y escribir nos garantiza un puesto privilegiado dentro de la sociedad.

Pero leemos en primera instancia por gusto. $Y$ ese gusto nace, como dijimos anteriormente, de experiencias placenteras en la infancia, la juventud y posteriormente, aunque en menor grado, en la edad adulta. El gusto crea el hábito y el hábito consolida al lector. Si queremos hallar la solución a los problemas de lectura tendremos que reflexionar sobre este asunto. Recordemos que al inicio de un gran lector hay un "modelo lector". ¿Pero qué es eso de un "modelo lector"?, se apresuraron a preguntar los docentes. Es les dije-, esa persona amada que le da por leernos libros o leer, como quien no quiere la cosa, delante de nosotros para obligarnos a leer con él, para que, astutamente, nosotros imitemos sus acciones, convencida, claro está, del respeto y el amor que le profesamos. Es

\footnotetext{
${ }^{2}$ El grupo de investigación IUDEX de la Universidad Surcolombiana, dentro de la investigación sobre los niveles de lectura de los estudiantes pregrado, trae a colación algunas teorias sobre la intención de la lectura y las estrategias cognitivas. Sucintamente, afirman que la intención de la lectura tiene distintas funciones: lectura profesional, informativa, ambiental, ritual y estética. Pero el lector, en últimas, no tiene una sola intención al leer un texto sino que las mezcla a su antojo de acuerdo a sus necesidades. Comprensión lectora: un enfoque cognitivo. Grupo de investigación IUDEX, Universidad Surcolombiana. Neiva, 2010. Pág. 17
} 
también ese apasionado que se presenta ante nosotros como el gran hechicero, un encantador que adormece serpientes leyéndoles libros y de su boca sale una invitación que no se puede rechazar.

Muy bonito, me dijeron los docentes. Sobre todo esa última parte de la serpiente. Y me atacaron con cierta maldad, convencidos que esta vez la serpiente del ejemplo me picaría: pero, díganos, profesor, ¿quién de los diversos miembros que conforman la comunidad educativa es ese ser que aman los estudiantes y es, además, un encantador de fobias y aburrimientos? En primer lugar los padres de familia, les dije. Pero los padres no leen, me replicaron. Son analfabetas funcionales, es decir, aprendieron a leer un día pero ahora no lo hacen, ocupados como están en los asuntos del trabajo y las finanzas de la casa. Tampoco leen los tíos ni las tías y tampoco los hermanos mayores, ocupados en la mayoría del tiempo en sus relaciones amorosas, el celular, el internet y la televisión.

Al final, concluí, entonces ¿sólo quedan ustedes? Los docentes se miraron y me dijeron: ¿y si nosotros tampoco leemos porque estamos ocupados en cientos de proyectos que nos carga el Ministerio y la Secretaría de Educación, el rector del colegio, el coordinador académico y hasta el alcalde y las juntas de acción comunal, eso sin contar con las obligaciones con el esposo y los hijos, la madre enferma o el hermano en problemas; si nosotros tampoco leemos, entonces, en donde encontraremos modelos lectores? Entonces, les respondí, es mejor que renuncien a su trabajo. En verdad, no tienen que renunciar, le dije. Es broma. Pero han de comprender que todas las razones que me dan sólo son excusas para no hacer un trabajo que les parece engorroso y aburrido. En verdad, si ustedes amaran los libros, su aproximación a ellos no sería un trabajo sino un goce y siempre tendría tiempo, inclusive en medio de las adversidades del trabajo y la vida. Ustedes se han olvidado del poder que tiene el enamorarse, apasionarse por algo en que se cree ciegamente. Si en verdad amaran la lectura serían capaces de grandes proezas.

Esta discusión me llevó a sospechar que muchos docentes habían perdido el encanto por la lectura, la habían convertido en un ejercicio frío para obtener información y planificar el trabajo en el salón de clases. Un día, en un ejercicio de exploración de la biblioteca municipal les pedí que tomaran un libro para leer, el que más les gustara. Luego de unos veinte minutos socializamos los textos seleccionados. Todos habían sido escogidos por su carácter utilitario: éste servía para desarrollar tal tema del currículo, aquel por que el esposo tenía interés por los autos, aquel otro porque ofrecia consejos prácticos para solucionar desórdenes emocionales. Mis sospechas eran ciertas. Los libros eran vistos por los docentes como instrumentos de trabajo. El libro era igual a trabajo; y si los libros eran vistos como trabajo tarde o temprano tendrían que agotarlos, representaban la carga del colegio, el esposo, la familia.

Exhorté a los docentes que dejaran de lado esa mala costumbre de la lectura utilitaria. Yo quería que leyeran por una vez en la vida algo totalmente "estúpido", "inútil" para los otros pero significativo para ellos mismos. Quería que escogieran un libro no porque era importante sino porque a ellos se les daba la regalada gana escogerlo y punto, así, de forma tajante y egoísta. Quería que procedieran de la misma forma que lo hacen sus alumnos cuando leen libros prohibidos en el baño de la institución. Al final, como era de esperarse, todos demostraron ser impotentes ante tan "inconcebible" solicitud.

Siempre consideré los talleres como un espacio de reflexión más que de acciones concretas, aunque a la larga ese era nuestro propósito. En todos los municipios del Huila, en todas las instituciones educativas con las que trataba 
siempre, sin excepciones, algunos o casi todos los docentes realizaban lecturas utilitarias y salían con las mismas excusas. Tenía entonces que convencerlos del poder de las lecturas gozosas y de la bondad de la escritura para la formación de los estudiantes y ellos mismos, para el progreso del país y la misma democracia. Y no era que ellos no lo supieran, era que simplemente no lo aplicaban. Hay un gran trecho entre tener una convicción y hacerla visible con acciones concretas. Yo recapitulaba todo lo que escuchaba y reflexionaba en las pequeñas habitaciones de los pueblos en los que me hospedaba. Trataba de darle la razón a los docentes: en verdad, los padres eran analfabetas funcionales, los docentes tenian mucho trabajo y la comunidad en general, empezando por el alcalde y los gremios no tomaban acciones concretas para promocionar la lectura aunque le profesaban respeto y decían en múltiples discursos públicos que esa actividad los sacaria de la ignorancia. Al no haber modelos lectores se replicaba la ignorancia una y otra vez.

\section{Ese asunto del plan lector institucional}

EI CERLALC nos había capacitado en la elaboración de Planes Lectores, herramienta valiosa para pasar de la convicción a las acciones. Algunas instituciones tenían Planes Lectores lo que me pareció un gran paso. Pero cuando les pedí que me explicaran en que consistía dicho plan me leyeron en voz alta un listado de libros que debían leer los estudiantes de primero a un undécimo grado. Este plan estaba justificado, por supuesto, en EL PEI y buscaba fortalecer el perfil de ciudadano que buscaba formar la institución. Yo les dije que eso no era un plan lector sino un listado de libros obligatorios que los padres debían comprar y los alumnos leer. Se estaba replicando el esquema de imposición y de obligatoriedad que llevaba a asociar los libros con la tortura y no con el goce. Un plan, les decía, más que un listado de libros valiosos -puesto que lo eran- es una serie de estrategias elementales que se implementan para solucionar un problema concreto. Tan simple como subirse a tapar una gotera en el cinc. El problema es que me cae una gotera en la cabeza, precisamente en la cama donde descanso; el origen del problema es que hay un agujero en el techo por el que se filtra el agua lluvia; la solución, comprar tapagoteras, subirme y taparlo. Y... ilisto! Maravilloso-!. En este punto los docentes se indignaban. Me decían que el problema de la lectura y escritura en el país no es tan simple como tapar una gotera. Por supuesto que no, les replicaba. Pero los mecanismos de solución son tan simples como éstos. No tienes que invertir mucho dinero ni capacitarse en Francia o en Japón. Ni siquiera tienen que ir a Bogotá. Lo haces aquí, en el salón de clase en donde verdaderamente se forman hombres de buen juicio y ciudadanos ejemplares.

El éxito de un plan lector institucional a corto y largo plazo -les insistía- es diagnosticar con precisión el problema y el origen del mismo. No darles vuelta una y otra vez al asunto, como quien camina en circulos. Decir que a los alumnos no les gusta leer porque así es la juventud de hoy en día no explica absolutamente nada. Hay que ir más al fondo. Yo exhortaba a los docentes para que me dieran otra respuesta. Algunos agregaban de pronto: "porque se aburren". ¿Y por qué se aburren sus estudiantes? Les insistía. Muchos respondian que era por pereza, que el internet los estaba consumiendo, que sus padres no ayudaban, que el rector no apoyaba los proyectos del profesor de español y que al final le echaban toda la culpa a los bajos niveles en las pruebas Saber y de Estado. Así que terminaban haciendo lo que podian. Es decir, poca cosa.

Desde el primer hasta el último año que trabajé con los docentes, siempre escuché las mismas quejas y descubri que el departamento del Huila sufre sin excepción, de los mismos dolores en materia de lectura y escritura. Luego de 
mucho discutir y reflexionar con los docentes se logró delimitar el problema y su origen. Problema: los estudiantes de las instituciones educativas del Huila no leen críticamente ni escriben textos significativos. Bueno, eso todo el mundo lo sabe. Pero era bueno escribirlo, verlo, revisarlo, reflexionar sobre el asunto. A partir de la reflexión se logró concretar tres circunstancias que originan el problema: 1) no hay modelos lectores en la familia; 2) los docentes no leen ni poseen estrategias pedagógicas dentro y fuera del aula de clase y; 3) los docentes no saben aprovechar las tecnologías en beneficio de propósitos educativos.

Lo que seguía entonces era la elaboración de las estrategias. Se les solicitó que elaboraran tres estrategias para contrarrestar cada una de las causas y el ingenio de los docentes apareció en todo su esplendor. En verdad, los docentes si habian implementado estrategias valiosas, pero en forma aislada y temporal. Habian sido experiencias exitosas que habían recibido el aplauso de las directivas, una palmadita en la espalda y luego se habían olvidado. El Plan Lector cambiaba las reglas de juego, institucionalizaba dichas estrategias y las proyectaba a corto y largo plazo, con evoluciones periódicas y cuantificables, y en cuya ejecución involucraba a todo el cuerpo de profesores y directivos, la familia, el alcalde y el municipio en su totalidad. Lo único que restaba era ponerse de acuerdo. Que todos "jalaran para el mismo lado". Pero eso era otro asunto.

En el segundo semestre del 2010, cuando La Secretaría de Proyecto Especiales del República, junto con la Organización Internacional para la Emigración de Suiza, OIM, me contrató para terminar un proyecto en los municipios de San Agustín y Pitalito ${ }^{3}$, también en relacionado con la lectura pero esta vez en la zona rural, me encontré con algunos docentes con los que habíamos elaborado el Plan Lector. El encuentro fue efusivo pero decepcionante. El Plan Lector fue institucionalizado en algunos colegios, en otros ni siquiera alcanzó ese estatus, pero en la mayoría de las instituciones había sido olvidado por completo. "Así pasa con la mayoría de los proyectos - me decía un docente- : nos hacen trabajar para cumplir con las normas. Trabajamos a la carrera, a prisa para cumplir con las fechas, presentamos el proyecto a tiempo, nos felicitan, luego sacamos disculpas para no ejecutarlo o hacerlo a medias; $y$ al final se archiva, se olvida. Sigue entonces que emprendemos otro y otro por orden del rector que a la vez está presionado por el director de Núcleo, que la vez está presionado por la Secretaria que a la vez esta presionada por el Ministerio. Este esquema se repite una y otra vez, año tras año. Al final cumplimos con las normas, pero ¿avanzamos?"

\section{Las estrategias del plan lector}

Solucionar el problema de la lectura y la escritura significativas no es tan fácil como tapar una gotera. Recuerdo a menudo este reclamo. Pero si tan simple como pedirle al niño que le escriba una carta a su padre pidiéndole el favor que le cuente cómo se conoció con su madre y que sintió en ese entonces; o tal vez tan simple como lo que hizo una profesora de Gigante: le pidió a sus niños que le escribieran a los soldados que habían pasado la navidad y el año nuevo en el monte, para saber cómo se sentían y si ellos podian ayudarlos en algo. Lo bueno del caso es que tanto los padres como los soldados respondieron y la escritura se convirtió en algo vital, interesante. La escritura tenía un fin, un

\footnotetext{
${ }^{3}$ Se trataba del proyecto denominado "El valor de la Palabra" dirigido a niños de la zona rural que tenía como objetivo desarrollar las competencias lectoras y contrarrestar el reclutamiento forzado por grupos al margen de la Ley
} 
sentido, y este simple ejercicio había cambiado el concepto que los niños tenían sobre la escritura, y de paso habían involucrado primero al padre, primer modelo lector, y a un sector de la comunidad, los soldados, que constituían una realidad palpable para todos los colombianos.

Así de simple era el plan de lectura. No debían viajar al exterior para que le enseñaran a escribir cartas, institucionalizar una hora de lectura gozosa para directivos, estudiantes y profesores, o cómo elaborar un cuestionario sobre los gustos y fobias de sus alumnos, un simple cuestionario que a simple vista parecía una necedad del docente pero que al final se convertiría en la mejor fuente de información para seleccionar los libros de lectura por gustos, edades e intereses. Con estas estrategias made in Gigante, por ejemplo, el panorama debía cambiar. Los libros se seleccionaban pensando en el estudiante para crear hábitos lectores. Después o simultáneamente vendrían los libros del currículo, los que seleccionamos los adultos por creerlos necesarios a todos los hombres del orbe. El plan lector también disponía de una biblioteca municipal con 3.200 libros bellamente editados que podía ser utilizado a sus anchas por los estudiantes y docentes. Los libros estaban clasificados por edades, por temas y niveles de lectura. Lo único que tenían que hacer las instituciones educativas era realizar acuerdo de cooperación con la biblioteca para llevar a cabo sus propósitos.

Las estrategias pedagógicas para aplicar en clase -incluyendo ios computadores, el internet, el video, la fotografía- no eran para nada novedosas aunque se involucrara la tecnología. Las tecnologías no son más que un cambio de soporte, claro está, más poderoso y a la vez más prometedor en cuanto que ubica a los estudiantes a nivel global. Recuerdo, por ejemplo, la institución educativa Las Toldas, ubicada en la vereda del mismo nombre, en el municipio de La Argentina. Antes de visitar una institución tenía la sana costumbre de indagar las pruebas Saber y de Estado de esa institución. Analizaba las debilidades y las fortalezas en competencias lectoras y en el caso Las Toldas quedé sorprendido. Los promedios de las Pruebas Saber superaban a la institución ubicada en el casco urbano e inclusive las de todo el departamento. ¿Qué había pasado?. Emprendí el viaje en moto hacia la institución, más que como funcionario del Ministerio, como de un hombre intrigado por lo que pasaba. La sede estaba emplazada en un terreno explanado, rodeada de café y cultivos de granadilla. No tenía biblioteca, los únicos libros eran las guías de clase, arrumadas en su mayoría en una especie de Cuarto de San Alejo. Confieso que dudé entonces de los resultados de las pruebas. ¿Habrían hecho trampa? No. Por supuesto que no. Los docentes de español e informática se habian unido hacia algunos años para solucionar el problema de los libros. Habian creado un software y en él habia transcrito muchos textos hermosos y estructurados ejercicios de comprensión lectora y escritura significativa. El resultado: en una institución rodeada de café y cultivos de granadilla, sin bibliotecas, sin libros impresos, los estudiantes se habian aficionado a la lectura a través de los medios tecnológicos y desarrollado sus competencias lectoras.

\section{Un matrimonio disfuncional}

Quizás lo que nos falta a los huilenses a la hora de solucionar los problemas no sea tanto dinero como buena voluntad y acciones concretas. Pero muchos de los docentes ya están cansados, se han estrellado una y otra vez con sus compañeros de trabajo con cada una de las iniciativas que emprenden; por otra parte, se han tenido que enfrentar al personal administrativo, los rectores, los directores de núcleo e inclusive con la Secretaría del Departamento y con el mismo Ministerio. Cumplir lo estrictamente necesario, a eso se reduce su labor como docente. Hay un cierto matrimonio disfuncional entre los docentes y las 
instituciones que velan por la calidad de la educación en nuestro país. Durante el proyecto que desarrollé con la Secretaría de Programa Especiales de la República y la OIM, visité regularmente unas veinte escuelas rurales del departamento durante aproximadamente cuatro meses. Recuerdo a una profesora a la que le habían advertido de mi visita. De entrada me percaté que tendria problemas. Estaba a la entrada de la escuela, hecha todo dientes y piedras en la mano. Casi no pude pronunciar palabra. Era franca y hablaba con rabia del abandono que la tenian en esa escuela en donde le tocaba hacer de todo y, para colmo, cumplir con los proyectos que inventaba la rectora, la junta de acción comunal, los padres de familia, la secretaria de educación y el Ministerio como si ella tuviera todo el tiempo del mundo. Yo la escuché en silencio durante más de media hora y al final no aguanté más: solté una enorme carcajada. Ella me miró sorprendida y con la misma rabia de un comienzo me preguntó por qué me reía. Le dije que estaba atacando $a$ un hombre que no estaba dispuesto a defenderse y que no venía a ponerle más trabajo. Sólo quería ayudarla. Entonces el ambiente enrarecido cambió y desde entonces terminamos trabajando en equipo. Algunas veces me la encontrara en la carretera montada en la moto, cargada de libros y me pitaba para saludarme. Y cada vez que la veía me causaba mucha risa: ahí va esa mujer tan brava -me decia-. Lástima, y tan bonita que es.

Me acostumbré a ver a los docentes como seres humanos y no como meros funcionarios. Durante los talleres había docentes que odiaban ir a la biblioteca porque el alcalde, encargado del funcionamiento y administración de la misma, les había hecho la guerra. Veian en la Biblioteca la extensión de la politiquería. El alcalde no los queria ver ni en pintura, mucho menos los iba a escuchar -me dijeron. Era una guerra de poderes. Por otra parte, algunos rectores habían negado todos los permisos para salir de la institución debido el mal comportamiento de los alumnos. Los docentes se cruzaban de brazos y decian: "Bueno, qué podemos hacer. Ya lo intentamos y no se pudo". Ocurría a veces que en los talleres los docentes dejaban caer una que otra bomba política al discurso y entonces yo tenía que buscar refugio para no salir lesionado. Y los dramas humanos no faltaban. Algunos docentes vivían colgados de una pena que de vez en cuando le anegaba los ojos. En el sur, una profesora empezó a llegar tarde a los talleres. No podía concentrarse y terminé preguntándole qué le pasaba. Me dijo que si se podía retirar. Le respondí lo que le siempre le decía a todos los docentes: si se siente mal o se aburren, pueden retirarse. Yo no me enfado por ello. La profesora entonces me confesó que su hija de quince años había quedado embarazada y se puso a llorar. Yo no supe que decir. Al final la profesora se retiró. Pero de pronto volvió al salón y me preguntó: ¿Y qué digo si el rector o el jefe de núcleo me ve en la calle? Dígale, le dije, que usted es la encargada de los refrigerios.

Existen docentes maravillosos. De esos que resisten todo y su proceder lo cuestionan a uno como tallerista: ¿y yo qué estoy haciendo aquí? -me preguntaba- ¿Cómo puede enseñar algo a estos docentes que me superan en experiencia, sensibilidad y conocimientos? En Gigante, una poeta dedicada a la docencia hacía Los Martes de Poesía; en Nátaga, otra docente había realizado actos públicos en torno al libro y la lectura; en Guadalupe, habían conjugado la manualidades con la literatura; en Gigante tenía una caja de libros donados por la comunidad y la sacaba a la hora del recreo para que los niños leyeran o jugaran con los libros; en lquira, un docente había creado un noticiero y permitía que los niños dramatizaran canciones; en La Argentina se había creado un software de lectura; en Salem, una vereda de San Agustín, los libros de lectura de los niños eran compartidos con los padres; en veredas de Pitalito, los docentes coleccionaban tiras cómicas y manualidades de los niños producto 
de la lectura, todo expuesto a la vista de todos para honrar a los creadores. De ellos aprendí que se puede hacer mucho con casi nada. Esos que hacen a pesar de todo, están casi olvidados. Algunas veces escuché quejas contra el rector, la Secretaría en inclusive contra los talleres que yo dirigía. ¿Qué podía hacer? Tenian razón en quejarse. Pero es mejor trabajar a cruzarse de brazos porque no nos apoyan. Al final los beneficiados son los niños y su bienestar es lo que importa. Esto lo entendian muy bien los docentes que ante mis ojos se fueron convirtiendo en verdaderos maestros y no en simples empleados del Estado.

\section{De las solicitudes hechas al tallerista}

Siempre traté de mantener mi profesión de escritor en secreto. En parte porque cuando dictaba los talleres me constituia en un funcionario del Estado y en parte porque pocos rectores y jefes de núcleo le creerían a un poeta. La primera dificultad en mi trabajo, como lo dije en un comienzo, era convencer a estos dos funcionarios. EI CERLALC, organismo encargado de la elaboración y ejecución del proyecto de lectura y bibliotecas, obrando en nombre del Ministerio de Educación, no nos daban ninguna identificación: ni carnet ni cartas de presentación. Temían que algún lugar de este país pudiéramos caer en manos de delincuentes, guerrilla o paramilitares. Nos presentábamos ante los rectores y jefes de núcleo únicamente de oídas. No había constancias que nos respaldaban, no había llamadas de ningún alto funcionario. La mayoría nos creyó. Una pequeña parte nos trató como embaucadores o vendedores de libros. Yo siempre les decía: vengo de parte del Ministerio de Educación. Si les hubiera dicho yo soy poeta y vengo a dictarles un taller, tiene que darles permiso a los docentes, tienen que apoyar sus iniciativas e institucionalizar un proyecto lector, ellos se las hubieran ingeniado para deshacerme de mi.
Estaba convencido que decir, de entrada, que yo era poeta no contribuía en nada. Lo veía como obstáculo para cumplir mi trabajo. Pero en el transcurso del tiempo los docentes descubrian que yo era escritor por alguna noticia en el periódico o por alguna infidencia de un conocido. Los docentes querían entonces que hiciera una visita formal a los estudiantes. Me pedían que me dirigiera a ellos y los aconsejara. En algunas ocasiones acepté y otras no lo hice por falta de tiempo. Ocurrió que hace un año la institución educativa Valencia de la Paz, ubicada en una vereda del municipio de lquira, me pidió que hablara con los niños. Habían leído mis libros y querian conocerme. Valencia la Paz es una institución que queda en la inspección del mismo nombre, en límites con el municipio de Teruel, lugar donde yo había nacido. En la infancia y la adolescencia, al otro lado de la montaña donde estaba la finca de mis padres, estaba Valencia de la Paz. Yo acostumbraba subir a hasta la cima y ver desde alli esa pequeña población de cultivadores de café, plátano, maíz y frijol. Inclusive había acompañado a mi padre los domingos a comprar café. Ahora los docentes querían convencer a los estudiantes que escribir y leer no es asunto de seres superiores sino de gente como ellos. $Y$ qué mejor que yo que compartía con ellos la misma tierra y los mismos alimentos, que habían crecido en Teruel y los había visitado en la adolescencia.

Fueron muchos los compromisos que me impidieron tal visita. Pero les envíe una carta que ahora y para finalizar este texto, quisiera reproducirla. Acaso contribuya en algo en la comprensión de la valoración los libros y la vida.

Neiva, 28 de abril de 2011.

Debo agradecer a la profesora Mercedes González y a la comunidad educativa de Valencia por haberme invitado a participar en el día del idioma. Debo agradecer ese gesto de generosidad que han tenido conmigo $y$ 
pedir a la vez disculpas por denegar dicha invitación debido a razones laborales. EI hecho de que hayan sido mis libros la primera noticia que hayan tenido de mí, me alegra inmensamente. Pues en verdad, los artistas valen por sus obras más que por su propia existencia. Si la existencia de un escritor fuera la base de su importancia para una comunidad, el día de su muerte la misma comunidad lo olvidaría. Pero en verdad, los verdaderos escritores permanecen a pesar de su muerte, viven en sus libros y desde las páginas de los libros siguen esclareciendo con su palabra al mundo.

Cada vez que un estudiante abre un libro, en verdad está hablando con un hombre que existió o existe en algún lugar de la Tierra. El estudiante habla con un hombre de carne y hueso. El libro, que es un hombre, lo invita entonces a dialogar. $Y$ esto es muy importante que lo entiendan: el libro jamás les dirá qué hacer, ni cómo

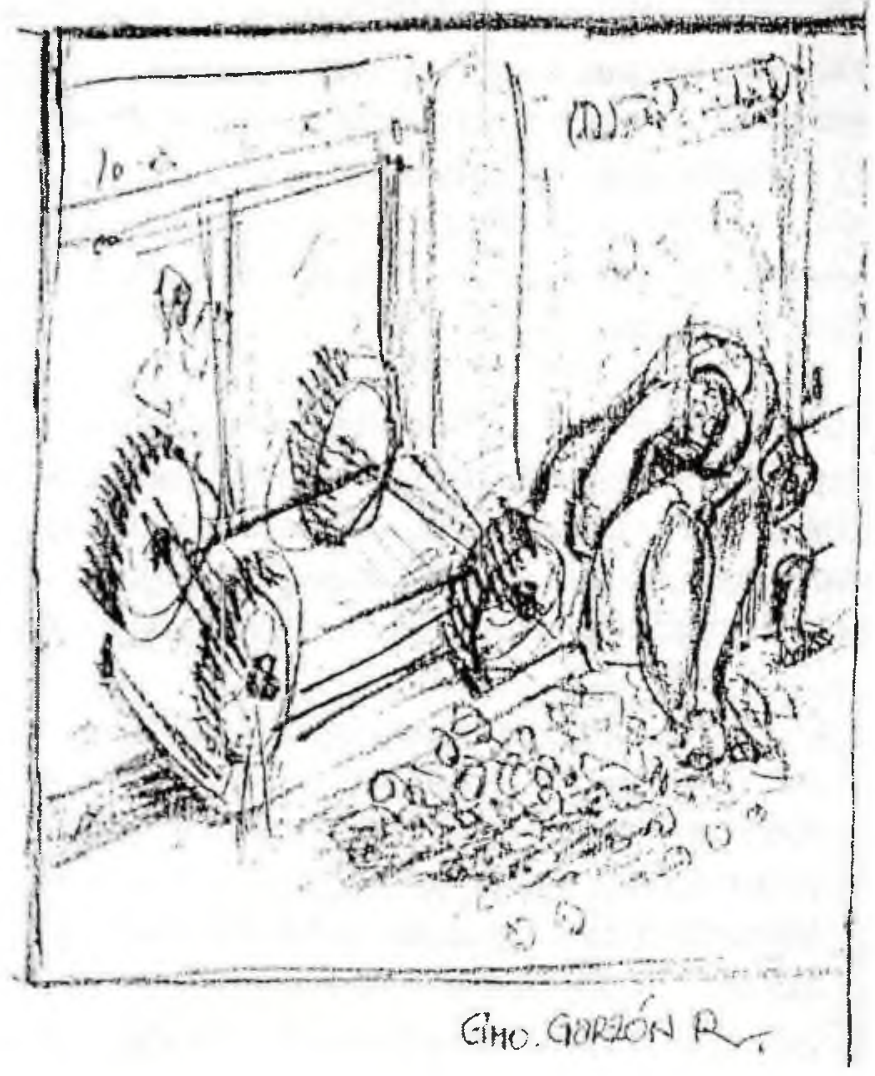

deben obrar en el mundo, ni cómo deben pensar. El libro solo quiere hablar con ustedes $y$, como en los más auténtico diálogos, ustedes tienen la última palabra, sacan sus propias conclusiones.

Creer ciegamente en los libros es estúpido. Los libros son como las personas. Algunas son muy inteligentes y nos aconsejan sabiamente; otras no lo son tanto y nos confunden y nos agobian. Así los libros: hay libros estúpidos y libros inteligentes, libros para torturar y libros para hacernos reír. Ustedes deben discernir frente a qué tipo de libros se encuentran y tener criterios para hacerlos sus amigos o dejarlos abandonados a la orilla de la carretera.

No se sabe cuántos libros hay en el mundo, ni cuántos hombres los han escrito o están escribiendo en este momento. Quizás miles de miles de millones. Ustedes jamás podrán leer todos los libros que existen en el planeta. Tendrían que morir y renacer miles de veces. Sólo les queda una opción: escoger los mejores. No perder el tiempo leyendo basura. Yo les doy una clave para que los sepan distinguir: los mejores libros son aquellos que te cuentan lo que tú no sabias, aquellos que te hacen ver el mundo de otra manera, los que te llenan de paz, los que te hacen reír y creer en la vida, los que te dicen de frente lo que tú eres y lo que no eres sin hipocresías. Son libros bien escritos, muy fáciles de leer. Y uno termina llevándolos a todas partes como si fuese otro de tantos amigos.

Leer esos libros acaso garantice un crecimiento espiritual y mental. Cuando las condiciones económicas no nos permiten conocer el mundo, los libros son una de las puertas de entrada a ese mundo al que queremos ir. ¿Qué los libros son aburridos? Sí, puede suceder que sean 
aburridos. Pero es bueno darles una oportunidad para que se defiendan. A lo mejor si abrimos un libro y escuchamos esa voz de la persona que lo escribió y consideramos cada una de sus palabras, terminaremos aprendiendo y gozando más de lo que esperábamos.

Yo los invito a leer y a escribir. Yo deseo que ustedes abran las puertas de sus mentes y dejen entrar a sus vidas los libros. Así como lo hice yo cuando tenía sus edades y vivía en el campo, y recogia café y me quedaba en las noches pensando en lo que había más allá de las montañas, más allá de Teruel, más allá del horizonte, y terminaba leyendo cuentos y poemas y ensayos. Y me dormía cansado como si le hubiera dado la vuelta al mundo a pie.

Mil gracias por la deferencia. Les deseos una buena, larga y fructifera vida a cada uno de ustedes.

Con aprecio, Jader Rivera Monje 